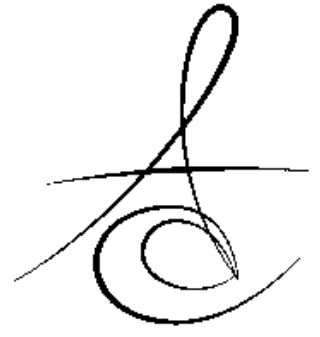

\section{TOPİKAL FLOR UYGULAMALARININ CAM İYONOMER ESASLI FİSSÜR ÖRTÜCÜ MATERYALLERİN MİKROSERTLİKLERİ ÜZERİNE ETKİSİ}

\section{EFFECT OF TOPICAL FLUORIDE APPLICATIONS ON THE MICROHARDNESS OF GLASS IONOMER BASED FISSURE SEALANTS}

Arş. Gör. Selçuk SAVAŞ*

Arş. Gör. Başak BÖLÜKBAŞI*

Yrd. Doç.Dr. Ebru KÜçÜKYILMAZ*

Makale Kodu/Article code: 1858

Makale Gönderilme tarihi: 25.09.2014

Kabul Tarihi: 10.12.2014

\section{ÖZET}

Amaç: Bu çalışmanın amacı, topikal flor uygulamalarının farklı içeriklerdeki cam iyonomer esaslı fissür örtücü materyallerin mikrosertlikleri üzerine olan etkilerinin incelenmesidir.

Metot: Çalışmada farklı içeriklere sahip cam iyonomer esaslı 3 adet fissür örtücü materyal kullanıldı (Fuji Triage, GCP Glass Seal, Fuji VII EP). Üretici firmaların talimatları doğrultusunda disk şeklinde hazırlanan 72 adet örnek $(8.0 \times 2.5 \mathrm{~mm})$, ışık tabancası (Valo, Ultradent Products Inc, South Jordan, UT, USA) ile polimerize edildi, 24 saat $37^{\circ} \mathrm{C}^{\prime} \mathrm{de}$, deiyonize su içerisinde bekletildikten sonra başlangıç mikrosertlik ölçümleri Vicker's mikrosertlik test cihazı (Shimadzu Micro Hardness Tester HMV-2, Shimadzu Corporation, Kyoto, Japan) ile gerçekleştirildi. Ölçümleri tamamlanan örnekler, rastlantısal olarak \%2'lik NaF (Sultan Topex neutral pH gel, Sultan Dental Products, USA) ve \%1,23'lük APF'nin (Sultan Topex APF gel, Sultan Dental Products, USA) uygulandığı 2 gruba bu gruplar da kendi içerisinde uygulama şekillerine göre 3 alt gruba ayrıldı (1dk jel uygulaması, $4 \mathrm{dk}$ jel uygulaması, $4 \times 4 \mathrm{dk}$ jel uygulaması). Uygulama sonrası örnekler deiyonize su ile yıkandı ve mikrosertlik ölçümleri tekrarlandı. İstatistiksel analizler, tekrarlanan ölçümlü ANOVA testi ve Bonferroni düzeltmesi ile gerçekleştirildi $(\alpha=0.05)$.

Bulgular: Uygulanan ajanın türü, uygulama süresi ve tekrarlayan uygulamaların, fissür örtücü materyallerin mikrosertlik değerlerini düşürdüğü ancak elde edilen değerler arasında istatistiksel olarak anlamlı bir fark olmadığı bulunmuştur $(p>0.05)$.

Sonuç: Çalışmada kullanılan farklı içeriklere sahip fissür örtücülerin yüzey sertlik değerlerinin çalışmada kullanılan topikal flor uygulamalarından etkilenmediği görülmüştür.

Anahtar Kelimeler: Fissür Örtücü, Mikrosertlik, Topikal Flor Uygulaması

\section{ABSTRACT}

Aim: The aim of this study was to assess the effect of topical fluoride applications on the surface microhardness of different glass ionomer based fissure sealants.

Method: In this study different glass ionomer based fissure sealants were used (Fuji Triage, GCP Glass Seal, Fuji VII EP). 72 disc shaped specimens (8.0x2.5 $\mathrm{mm}$ ) which were prepared according to manufacturer's instructions were photopolimerized with light source (Valo, Ultradent Products Inc, South Jordan, UT, USA), after stored in distilled water at $37^{\circ} \mathrm{C}$ for 24 hour initial microhardness measurements were performed with Vicker's microhardness tester (Shimadzu Micro Hardness Tester HMV-2, Shimadzu Corporation, Kyoto, Japan). Specimens were randomly assigned to 2 experimental groups according to surface treatment regimens consisting of $2 \% \mathrm{NaF}$ gel (Sultan Topex neutral pH gel, Sultan Dental Products, USA) and $1.23 \% A P F$ gel (Sultan Topex APF gel, Sultan Dental Products, USA) and these groups were assigned to 3 experimental subgroups according to application types (1 minute gel application, 4 minute gel application, $4 \times 4$ minute gel application). After applications; specimens were rinsed with distilled water and microhardness measurements were repeated. Statistical analysis were made with repeated measures ANOVA and Bonferroni correction ( $\alpha=0.05$ ).

Result: It has been found that the types of applied agents, time of application and repeated applications reduce the hardness values of fissure sealant material, but the difference was not statistically significant $(p>$ 0.05).

Conclusion: Microhardness values of the different content fissure sealants used in the study were found not to be affected by topical fluoride applications.

Keywords: Fissure Sealant, Microhardness, Topical Fluoride Application

\footnotetext{
*İzmir Katip Çelebi Üniversitesi, Diş Hekimliği Fakültesi, Pedodonti Anabilim Dalı,
} 


\section{GİRIŞ}

Posterior dişlerdeki pit ve fissürler anatomik olarak, çürük oluşumuna sebep olan mikroorganizmaların yapışmasını kolaylaştıran, çürüğe hassas bölgelerdir. Okluzal çürüklerin yüksek oranda oluştuğu bu bölgelerde, çürük oluşumunu önlemek amacıyla fissür örtücüler sıklıkla uygulanmaktadır. ${ }^{1}$ Fissür örtücüler, diş yüzeyinde koruyucu bir tabaka oluşturarak çürüğe yatkın pit ve fissürlere karyojenik bakterilerin ve bakteri besinlerinin ulaşmasını ve tutunmasını engelleyen ve bir çeşit bariyer görevi gören materyaller olarak tanımlanmaktadır. ${ }^{2,3}$ Koruyucu diş hekimliğinde tedavi planlamasında önemli bir yeri olan fissür örtücü uygulamaları sayesinde pit ve fissür çürükleri etkili bir şekilde önlenebilmektedir. ${ }^{4}$

Fissür örtücü olarak uygulanan materyaller rezin ve cam iyonomer bazlı olarak ikiye ayrılmaktadır. $^{5}$ Cam iyonomer (CIS) esaslı fissür örtücüler, diş dokularına kimyasal olarak bağlanabilmeleri, flor salabilme özellikleri, biyolojik olarak uyumlu olmaları, antibakteriyel etkileri, hidroksiapatit kristallerinin remineralizasyonunu sağlayabilmeleri gibi faydalarından dolayı özellikle pediatrik diş hekimliğinde yüksek çürük riskli hastalarda iyi bir tedavi alternatifi olarak değerlendirilmektedir. ${ }^{5-9} \mathrm{Bu}$ avantajların yanında cam iyonomer simanlar, hem neme hem de aşırı kuruluğa karşı duyarlı materyallerdir.,8 Geleneksel cam iyonomerlerin fiziksel eksikliklerinin üstesinden gelmek amacıyla rezin modifiye cam iyonomerler ve yüksek viskoziteli cam iyonomerler geliştirilmiştir ve bu materyallerin restoratif materyal olarak daha uzun ömürlü olarak kullanılabileceği yapılan klinik çalışmalarla desteklenmiştir. ${ }^{10,11} \mathrm{Bu}$ amaçla son zamanlarda geliştirilen kazein fosfopeptit-amorföz kalsiyum fosfat (CCP-ACP) ve nano-fluoroapatit/hidroksiapatit içerikli cam iyonomer materyaller dikkat çekici görünmektedir. ${ }^{12}$ Cam iyonomer materyallere CPP-ACP ilavesini değerlendiren çalışmalar, CPP-ACP'nin flor varlığında stabil olduğunu, flor ile sinerjik bir etkileşim göstererek kalsiyum ve fosfat salımının arttığını göstermektedir. ${ }^{13,14}$ Cam iyonomer materyallere nano-fluoroapatit/hidroksiapatit ilavesini irdeleyen çalışmalar incelendiğinde ise, bu ilaveler ile cam iyonomerlerin bağlanma dayanımı ve aşınma gibi fiziksel özelliklerinde iyileşme olduğu görülmektedir. ${ }^{15}$

Yüksek çürük riskine sahip hastaların koruyucu tedavi planlamasında fissür örtücülere ilave olarak flor içerikli diş macunları, ağız gargaraları, topikal jeller gibi çürük riskini azaltıcı uygulamaların da dahil edilmesi tavsiye edilmektedir. ${ }^{16}$ Topikal flor uygulamaları diş sert dokularının direncini artırarak diş çürümelerine karşı diş yüzeyin korunmasında etkilidir. ${ }^{17}$ Orta ya da yüksek çürük risk grubundaki hastalarda çeşitli flor ajanları çürüğe karşı koruyucu olarak uygulanabilir, fakat demineralizasyon sürecini engelleyen ve remineralizasyon fazını indüklemede etkili olan optimum flor konsantrasyonu ve süresi konusunda fikir ayrılıkları devam etmektedir. ${ }^{18,19}$

Günümüzde piyasada profesyonel olarak uygulanan farklı içerik ve $\mathrm{pH}$ değerlerine sahip flor jeli alternatifleri bulunmaktadır. Sodyum florid (NaF), asidüle fosfat florid (APF), stannöz florid $\left(\mathrm{SnF}_{2}\right)$ ve amin florid (AmF) çürüğe karşı koruyucu olarak yıllardır kullanılan flor ajanları olmakla birlikte APF ve $\mathrm{NaF}$ içeren ajanlar klinik olarak en sık kullanılanlarıdır. ${ }^{20}$ Topikal olarak uygulanan flor jellerinin, içeriği ve $\mathrm{pH}$ değerlerine bağlı olarak, cam iyonomer esaslı restoratif materyallerin yüzeyini etkilediğini gösteren çalışmalar bulunmaktadır. ${ }^{21,22} \mathrm{Bu}$ doğrultuda, yeni geliştirilmiş cam iyonomer esaslı dental materyaller üzerine florun olası yan etkilerinin belirlemesi için çalışmalara intiyaç vardır. Bu nedenle, bu çalışmada 1 ve 4 dakikalık 1,23\% APF ve \% $2 \mathrm{NaF}$ uygulamalarının farklı içeriklerdeki cam iyonomer esaslı fissür örtücü materyallerin mikrosertlikleri üzerine olan etkilerinin belirlenmesi amaçlanmıştır. Çalışmada flor jeli uygulamalarının, incelenen dental materyallerin mikrosertlikleri üzerindeki etkileri arasında istatiksel olarak anlamlı bir fark olmayacağı sıfır hipotezi olarak kabul edilmiştir.

\section{MATERYAL ve METOD \\ Örneklerin Hazırlanması}

Çalışmada kullanılan cam iyonomer içerikli fissür örtücü materyaller (GCP Glass Seal, Fuji VII EP, Fuji Triage [Tablo 1]) her materyalden 72 adet disk oluşturmak amacıyla üretici firmanın talimatları doğrultusunda $8.0 \mathrm{~mm}$ iç çap ve $2.5 \mathrm{~mm}$ kalınlıktaki tek kullanımlık teflon kalıplara yerleştirildi ve iki mylar strip ile preslendi. Tüm örnekler üretici firmaların önerileri doğrultusunda ışık kaynağı (Valo, Ultradent Products Inc, South Jordan, UT, USA) kullanılarak Tablo 1'de belirtildiği şekilde polimerize edildi. Işık kaynağı ve örnekler arasındaki mesafe $1 \mathrm{~cm}$ kalınlığındaki bir cam levha kullanılarak standardize 
Tablo 1. Çalışmada kullanılan materyallerin lot numaraları, içerikleri ve uygulama prosedürleri

\begin{tabular}{|c|c|c|}
\hline & İçerik & Uygulama Prosedürleri \\
\hline $\begin{array}{l}\text { Fuji Triage } \\
\text { (\#1202091, } \\
\text { GC Int., } \\
\text { Tokyo, } \\
\text { Japan) }\end{array}$ & $\begin{array}{l}\text { Cam iyonomer, } \\
\text { aluminofluoro-silikate } \\
\text { cam partikülleri, } \\
\text { poliakrilik asit, distile } \\
\text { su, renklendirici, } \\
\text { karboksilik asit }\end{array}$ & $\begin{array}{l}\text { 1.Karıştırıcıya yerleştirmeden } \\
\text { önce kapsül çalkalanır. } \\
2.10 \text { saniye boyunca yüksek } \\
\text { hızda karışııılır. } \\
\text { 3.Tabancaya yerleştirilir, iki kere } \\
\text { basılır ve uygulanır. } \\
\text { 4.GC Fuji Coat LC uygulanır ve } \\
\text { polimerize edilir. }\end{array}$ \\
\hline $\begin{array}{l}\text { Fuji VII EP } \\
\text { (\#1204041, } \\
\text { GC Int., } \\
\text { Tokyo, } \\
\text { Japan) }\end{array}$ & $\begin{array}{l}\text { Fluoroaluminosilikat } \\
\text { cam partikülleri, CPP- } \\
\text { ACP, poliakrilik asit, } \\
\text { distile } \\
\text { renklendirici, } \\
\text { karboksilik asit }\end{array}$ & $\begin{array}{l}\text { 1.Karıştıııcıya yerleştirmeden } \\
\text { önce kapsül çalkalanır. } \\
2.10 \text { saniye boyunca yüksek } \\
\text { hızda karıştırıır. } \\
\text { 3.Tabancaya yerleştirilir, iki kere } \\
\text { basılır ve uygulanır. } \\
\text { 4.GC Fuji Coat LC uygulanır ve } \\
\text { polimerize edilir. }\end{array}$ \\
\hline $\begin{array}{l}\text { GCP Glass } \\
\text { Seal } \\
\text { (\#7301088, } \\
\text { GCP Dental, } \\
\text { Vianen, } \\
\text { the } \\
\text { Netherlands) }\end{array}$ & $\begin{array}{l}\text { Nano boyutlu cam } \\
\text { partikülleri, } \\
\text { nanofluoro/hidroksiap } \\
\text { atit, likit silika }\end{array}$ & $\begin{array}{l}\text { 1.Karıştırıcıya yerleştirmeden } \\
\text { önce kapsül çalkalanır. } \\
2.10 \text { saniye boyunca yüksek } \\
\text { hızda karıştırıır. } \\
\text { 3.Tabancaya yerleştirilir, iki kere } \\
\text { basılır ve uygulanır. } \\
\text { 4.GCP Gloss uygulanır ve } \\
\text { polimerize edilir. }\end{array}$ \\
\hline $\begin{array}{l}\text { GCP Gloss } \\
\text { (\#1307076, } \\
\text { GCP Dental, } \\
\text { Vianen, } \\
\text { the } \\
\text { Netherlands) }\end{array}$ & Modifiye Polisiloksan & $\begin{array}{l}\text { 1.Tek kullanımlık mikrofırça } \\
\text { yardımıyla ince bir tabaka halinde } \\
\text { restoratif materyalin tamamına } \\
\text { uygulanır. } \\
2.60-90 \text { saniye ışık uygulanır. }\end{array}$ \\
\hline $\begin{array}{l}\text { Fuji Coat } \\
\text { LC } \\
\text { (\#1310241, } \\
\text { GC Int., } \\
\text { Tokyo, } \\
\text { Japan) }\end{array}$ & $\begin{array}{l}\text { Multifonksiyonel } \\
\text { üretan metakrilat, } \\
\text { alifatik } \\
\text { dimetakrilat,metil } \\
\text { metakrilat, tersiyer } \\
\text { amin }\end{array}$ & $\begin{array}{l}\text { 1.Tek kullanımlık mikrofırça } \\
\text { yardımıyla ince bir tabaka halinde } \\
\text { restoratif materyalin tamamına } \\
\text { uygulanır. } \\
2.60-90 \text { saniye ışık uygulanır. }\end{array}$ \\
\hline & & \\
\hline
\end{tabular}

edildi. Teflon kalıptan çıkarılan örnekler, 24 saat 37 derecede deiyonize su içerisinde bekletildi. Bu işlemin ardından örneklerin her iki yüzeyi akan suyun altında 600 ve 1200 gritlik zımpara ile zımparalandı. Örnekler, başlangıç ölçümleri sonrası her grupta 12 örnek olacak şekilde rastgele 6 gruba ayrıldı.

Grup I: 1 dakika \% 1.23 APF uygulaması $(n=12)$

Grup II: 4 dakika \% 1.23 APF uygulaması $(n=12)$

Grup III: 4 X 4 dakika \% 1.23 APF uygulaması $(n=12)$

Grup IV: 1 dakika $\% 2 \mathrm{NaF}$ uygulaması $(n=12)$

Grup V: 4 dakika $\% 2 \mathrm{NaF}$ uygulaması $(n=12)$

Grup VI: 4 X 4 dakika \% 2 NaF uygulaması $(n=12)$

$\mathrm{NaF}$ (Sultan Topex neutral pH gel, Sultan

Dental Products, USA) ve APF (Sultan Topex APF gel, Sultan Dental Products, USA) uygulamaları örneklerin üst yüzeylerine yapıldı. Uygulamadan hemen sonra örnekler, üzerlerinde flor artığı kalmayacak şekilde dei- yonize su ile yıkandı ve üst yüzeylerinden mikrosertlik ölçümü yapıldı. Flor jellerinin 4 kere uygulandığı gruplarda her uygulama sonrası örnekler deiyonize su ile yıkandı ve her bir uygulama arasında 30 dakika beklendi.

\section{Mikrosertlik Değerlendirmesi}

Yüzey değerlendirmesi yapılan örneklerin üst yüzeylerinden başlangıç ve flor uygulaması sonrası mikro sertlik ölçümleri Vicker's sertlik test cihazı (Shimadzu Micro Hardness Tester HMV-2, Shimadzu Corporation, Kyoto, Japan) ile yapıldı. Vicker's mikrosertlik testi için piramit bir elmas uç ile $50 \mathrm{~g}$ 'lık kuvvet 20 sn süreyle uygulandı. Üç nokta testi her numunede rastgele olarak yapıldı ve anlamlı değer hesaplandı. İstatistiksel analizler, tekrarlanan ölçümlü ANOVA testi ve Bonferroni düzeltmesi ile gerçekleştirildi. Değerlendirmeler için istatistiksel önem aralı̆̆ı $p<0.05$ olarak kabul edildi.

\section{BULGULAR}

Çalışmada test edilen materyallerin yüzey uygulamaları öncesi ve sonrası mikrosertlik değerleri Tablo 2'de gösterilmektedir. Materyallerin mikrosertlik değerlerini en çok düşüren uygulama Fuji Triage materyali için $4 \mathrm{dk}$ APF uygulaması olurken, Fuji VII EP ve GCP Glass Seal için $4 \times 4$ dk APF uygulaması olmuştur. Bununla birlikte, uygulanan ajanın türü, uygulama süresi ve tekrarlayan uygulamaların, fissür örtücü materyallerin mikrosertlik değerlerini düşürdüğü ancak üç materyal kendi aralarında karşılaştırıldığında elde edilen değerler arasında istatistiksel olarak anlamlı bir fark olmadığı bulunmuştur. $(p>0.05)$

Tablo 2. Çalışmada elde edilen ortalama mikrosertlik değerleri ve standart sapmaları

\begin{tabular}{|c|c|c|c|}
\hline & Fuji Triage & Fuji VII EP & $\begin{array}{c}\text { GCP Glass } \\
\text { Seal }\end{array}$ \\
\hline & Ortalama \pm SS & Ortalama \pm SS & Ortalama \pm SS \\
\hline Başlangıç & $38,20 \pm 4,97^{a}$ & $28,01 \pm 6,70^{\mathrm{a}}$ & $35,23 \pm 2,96^{a}$ \\
\hline APF 1 DK & $35,77 \pm 4,40^{a}$ & $27,27 \pm 6,03^{a}$ & $33,92 \pm 2,74^{a}$ \\
\hline APF 4 DK & $34,11 \pm 4,96^{a}$ & $27,98 \pm 7,28^{a}$ & $33,88 \pm 5,63^{a}$ \\
\hline APF $4 X 4$ DK & $34,42 \pm 3,35^{\mathbf{a}}$ & $23,18 \pm 7,28^{a}$ & $32,68 \pm 2,74^{a}$ \\
\hline NaF 1 DK & $38,03 \pm 3,77^{a}$ & $27,91 \pm 5,49^{a}$ & $34,19 \pm 6,24^{a}$ \\
\hline NaF 4 DK & $35,56 \pm 5,96^{a}$ & $27,92 \pm 3,75^{a}$ & $34,98 \pm 3,24^{a}$ \\
\hline NaF 4X4 DK & $36,58 \pm 8,87^{a}$ & $24,72 \pm 11,30^{\mathrm{a}}$ & $34,96 \pm 4,38^{a}$ \\
\hline \multicolumn{4}{|c|}{$\begin{array}{l}\text { *SS: Standart Sapma, DK: Dakika } \\
\text { *Harfler gruplar arasındaki istatistiksel farkları betimlemek amacıyla } \\
\text { kullanılmıstır }(p<0.05) \text {. }\end{array}$} \\
\hline
\end{tabular}




\section{TARTIŞMA}

Pit ve fissürlerdeki çürük önleyici etkinlikleri birçok çalışma ile kanıtlanmış olan fissür örtücüler, özellikle koruyucu tedavi planlamasının önemli bir basamağıdır. ${ }^{23,24}$ Cam iyonomer esaslı fissür örtücüler, diş dokularına kimyasal olarak bağlanabilme, flor salımı yapabilme ve hidrofilik özellikleri ile çocuk diş hekimliğinde sıklıkla tercih edilen materyallerdir. ${ }^{25,26}$ Cam iyonomerler ayrıca solüsyonlar, jeller ve macunlar gibi flor içerikli ajanların uygulanması sonrası, reşarj edilebilen ve flor rezervuarı olarak görev yapan materyallerdir. ${ }^{27}$ Bununla birlikte, cam iyonomerler, topikal flor uygulamaları sonrası oluşan yüzey değişiklikleri açısından hassas materyallerdir. ${ }^{28}$ Cam iyonomer materyaller üzerine uygulanan topikal flor tedavileri erozyon ve madde kaybına yol açarak materyalin yüzey pürüzlülüğünü arttırıp yüzey sertliğini azaltabilmektedir. Bilinmektedir ki bir dental materyalin sertlik kaybı klinik başarısını olumsuz etkileyerek anatomik şeklini kaybetmesine ve renklenmesine sebep olabilmektedir. ${ }^{29} \mathrm{Bu}$ nedenle mevcut çalışmada, iki farklı flor jelinin, fissür örtücü olarak kullanılan cam iyonomer içerikli materyallerin mikrosertlikleri üzerine olan etkilerinin değerlendirilmesi amaçlanmıştır. Çalışma sonuçlarına göre, flor jeli uygulamalarının, incelenen dental materyallerin mikrosertlikleri üzerindeki etkileri arasında istatiksel olarak anlamlı bir fark olmayacağı sıfır hipotezi kabul edilmiştir. Bununla birlikte, kulla- nılan topikal flor ajanları içerisinde, her üç materyalin mikrosertliğini en az düşüren uygulamaların NaF uygulamaları olduğu görülmektedir. $\mathrm{Bu}$ sonucun $\mathrm{NaF}$ jelinin nötral pH'ta olması ve asit içeriğinin bulunma- masından kaynaklandığı düşünülmektedir. Mevcut çalışma sonuçları ile uyumlu olarak, Akselsen ve Rolla ${ }^{30}, \mathrm{NaF}(2 \%)$ ve SnF (8\%) uygulamalarının, rezin modifiye cam iyonomer ve poliasit modifiye rezin kom- pozitlerde belirgin bir yüzey pürüzlülüğü oluştur- madığını göstermişlerdir.

Materyallerin mikrosertlik değerlerini en çok düşüren uygulama Fuji Triage materyali için $4 \mathrm{dk}$ APF uygulaması olurken, Fuji VII EP ve GCP Glass Seal için 4x4 dk APF uygulaması olmuştur. Crisp ve arkadaşlarına göre, APF; asidik pH değeri nedeniyle, materyal yüzeyinde pürüzlendirme etkisi oluşturarak $\mathrm{Na}, \mathrm{Ca}, \mathrm{Al}$, ve $\mathrm{Sr}$ iyonlarından oluşan bir matris oluşturmasının yanında flor salınımını arttıran bir kimyasal erozyona yol açmaktadır. ${ }^{31}$ Cam iyonomerdeki erozyon miktarı
$\mathrm{pH}^{\prime} ı$ n yanında özellikle materyalin sahip olduğu asit içeriğinden de etkilenmektedir. ${ }^{32} \mathrm{APF}$, restoratif materyallerde çözünmeye neden olabilen fosforik asit ve hidroflorik asit içerir. ${ }^{33}$ APF' deki fosforik asit, iyonomer içeriğindeki metal iyonları ile stabil kompleksler oluşturarak geniş yüzey erozyonlarına neden olabilmekte ve cam partiküllerini pürüzlendirmektedir. ${ }^{33}$ Hidroflorik asit ise düşük ısılarda bile pürüzlendirme yapabilen daha yıkıcı bir etkiye sahiptir. ${ }^{30}$ Bununla birlikte, çalışmada kullanılan APF ve NaF jel uygulama prosedürleri sonrası oluşan mikrosertlik kayıpları kendi aralarında karşılaştırıldığında istatiksel olarak anlamlı fark bulunamamıştır. Bu bulgular Topaloğlu ve ark. ${ }^{34}$ ve Garcia-Godoy ve ark.'nın ${ }^{35}$ yaptığı çalışmaların sonuçlarıla benzerlik göstermektedir. Setty ve ark. ${ }^{27}$ ile Arnold ve ark. da ${ }^{36}$ APF uygulamasının NaF uygulaması ile karşılaştırıldığında belirgin derecede yüzey sertliğini azalttığını bildirmişlerdir.

Topikal flor jellerinin, restoratif materyallerin mikrosertlikleri üzerine etkilerini inceleyen birçok çalışmada kıyaslama yapılabilmesi amacıyla, nötr ve asidik pH'a sahip farklı topikal flor jelleri kullanılmaktadır. Çalışmamızda da klinik olarak en sık kullanılan flor jelleri olan NaF ve APF jelleri tercih edilmiştir. Çalışmada farklı uygulama zamanlarının tercih edilmesinin nedeni, çalışmalarda restoratif materyallerin yüzey kaybının uygulama zamanına bağlı olarak değişebildiğinin rapor edilmesi ve firmalar tarafından önerilen uygulama zamanlarının farklı olmasıdır. ${ }^{12,30}$ Üretici firmalar NaF uygulaması için 4 dakikalık uygulama önerirken, APF uygulaması için 1 veya 4 dakikalık uygulamaları önermektedirler. Bunun yanında, $4 \mathrm{kez}$ tekrarlanan 4 dakikalık uygulama prosedürünün test edilmesinin nedeni ise tekrarlanan uygulamaların materyal yüzeyindeki etkilerinin belirlenmesidir. Bu uygulamalar uzun süreli klinik etkileri tam olarak belirlemese de topikal jellerin ortalama potansiyel etkilerini yansıtmaktadır. Bununla birlikte ağız ortamında tükürük proteinlerinin varlığının materyal yüzeyinde koruyucu bir etki oluşturabileceği veya ortam pH'ındaki değişikliklerin sertlik değerlerini etkileyebileceği göz önünde bulundurulmalıdır.

Mevcut çalışmada kullanılan materyallerden Fuji VII EP ve GCP Glass Seal yeni geliştirilmiş cam iyonomer esaslı fissür örtücülerdir. Fuji VII EP, Fuji Triage'ın içeriğine \%5 oranında CPP-ACP ilavesiyle elde edilmiştir ve yapısındaki CCP-ACP sayesinde, materyalin çürük önleyici etkinliğinin arttırılması amaç- 
lanmıştır. ${ }^{37,38}$ Yeni geliştirilmiş bir diğer materyal olan GCP Glass Seal, nano boyutta partiküllerden oluşan doldurucu içeren, ikincil olarak da florapatit doldurucuya sahip materyallerdir. Nanoteknolojik florapatit kristalleri ilavesi sayesinde malzemenin remineralizasyon kabiliyetinin ve fiziksel özelliklerinin piyasadaki mevcut cam iyonomer esaslı fissür örtücülere kıyasla daha iyi olduğu iddia edilmektedir. ${ }^{39,40}$ Çalışma sonuçlarına göre, materyallerin başlangıç mikrosertlik değerlerinin birbirlerinden farklı olduğu görülmektedir. Bununla birlikte, topikal flor uygulamalarının malzemelerin mikrosertlikleri üzerine etkisi açısından, farklı içeriklere ve farklı başlangıç mikrosertlik değerlerine sahip fissür örtücülerin kullanımının, bir farklılık yaratmadığı görülmektedir.

\section{SONUÇ}

Çalışmada kullanılan farklı içeriklere sahip cam iyonomer esaslı fissür örtücülerin yüzey sertlik değerlerinin değerlendirilen topikal flor uygulamalarından etkilenmediği görülmüştür.

\section{KAYNAKLAR}

1. Guler C, Yilmaz Y. A two-year clinical evaluation of glass ionomer and ormocer based fissure sealants. J Clin Pediatr Dent 2013;37:263-7.

2. Simonsen, RJ. Pit and fissure sealant: review of the literature. Pediatr Dent 2002;24:393-414.

3. Marks D, Owens, BM, Johnson WW. Effect of adhesive agent and fissure morphology on the in vitro microleakage and penetrability of pit and fissure sealants. Quintessence Int 2009;40:763-72.

4. Ahovuo-Saloranta A, Hiiri A, Nordblad A, Mäkelä M, Worthington HV. Pit and fissure sealants for preventing dental decay in the permanent teeth of children and adolescents. Cochrane Database Syst. 2008;Rev. 8:CD001830.

5. Davidovich $E$, Weiss $E$, Fuks AB, Beyth N. Surface antibacterial properties of glass ionomer cements used in atraumatic restorative treatment. J Am Dent Assoc 2007;138:1347-52.

6. Modena KC, Casas-Apayco LC, Atta MT, Costa CA, Hebling J, Sipert CR, Navarro MF, Santos CF. Cytotoxicity and biocompatibility of direct and indirect pulp capping materials. J Appl Oral Sci 2009;17:544-54.
7. Hallgren A, Oliveby A, Twetman S. The state of the art of the ART restorations. Dent Update 2014;41:218-20.

8. Valk JW, Davidson CL. The relevance of controlled fluoride release with bonded orthodontic appliances. J Dent 1987;15:257-260.

9. Bynum AM, Donly KJ. Enamel de/remineralization on teeth adjacent to fluoride releasing materials without dentifrice exposure. ASDC J Dent Child 1999;66:89-92.

10. Qvist V, Manscher E, Teglers PT. Resin-modified and conventional glass ionomer restorations in primary teeth: 8-year results. J Dent 2004;2:28594.

11. Faccin ES, Ferreira SH, Kramer PF, Ardenghi TM, Feldens CA. Clinical performance of ART restorations in primary teeth: a survival analysis. J Clin Pediatr Dent 2009;33:295-8.

12. Mazzaoui SA1, Burrow MF, Tyas MJ, Dashper SG, Eakins D, Reynolds EC. Incorporation of casein phosphopeptide-amorphous calcium phosphate into a glass-ionomer cement. J Dent Res 2003; 82:914-8.

13. Cochrane NJ, Reynolds EC. Calcium phosphopeptides -- mechanisms of action and evidence for clinical efficacy.. Adv Dent Res 2012;24:41-7

14. Reynolds EC. The prevention of sub-surface demineralization of bovine enamel and change in plaque composition by casein in an intraoral model. J Dent Res 1987;66:1120-7

15. Van Duinen RN, Davidson $C L$, De Gee $A J$, Feilzer AJ. In situ transformation of glass-ionomer into an enamel-like material. Am J Dent 2004;17:223-7.

16. Marinho VC. Cochrane reviews of randomized trials of fluoride therapies for preventing dental caries. Eur Arch Paediatr Dent 2009;10:183-91.

17. Demirci M, Ucok M. Hibrit iyonomer materyallerin florür salınımı. Atatürk Üniv Dis Hek Fak Derg 2000;10:61-5

18. Erickson RL, Glasspoole EA. Model investigations of caries inhibition by fluoride-releasing dental materials. Adv Dent Res 1995;9:315-23.

19. Turssi $C P$, de Magalhães CS, Serra MC. Effect of fluoride gels on micromorphology of resin-modified glass-ionomer cements and polyacidmodified resin composites. Quintessence Int 2001;32:571-7. 
20. Van Rijkom H, Ruben J, Vieira A, Huysmans MC, Truin GJ, Mulder J. Erosion-inhibiting effect of sodium fluoride and titanium tetrafluoride treatment in vitro. Eur J Oral Sci 2003;111:253-7.

21. Cehreli ZC, Yazici R, García-Godoy F. Effect of 1.23 percent APF gel on fluoride-releasing restorative materials. ASDC J Dent Child 2000;67:330-7.

22. Yip HK, Lam WT, Smales RJ. Surface roughness and weight loss of esthetic restorative materials related to fluoride release and uptake. J Clin Pediatr Dent 1999;23:321-6.

23. Mejàre I, Lingström $P$, Petersson LG, Holm AK, Twetman S, Källestål C, et al. Caries-preventive effect of fissure sealants: a systematic review. Acta Odontol Scand 2003;61:321-30.

24. Neusser S, Krauth C, Hussein R, Bitzer EM. Clinical effectiveness and cost-effectiveness of fissure sealants in children and adolescents with a high caries risk. GMS Health Technol Assess 2014;1:10.

25. Smith DC. Polyacrylic acid-based cements-adhesion to enamel and dentin. Oper Dent 1992;Suppl 5:177-83.

26. Khoroushi M, Keshani F.. A review of glassionomers: From conventional glass-ionomer to bioactive glass-ionomer. Dent Res J (Isfahan) 2013;10:411-20.

27. Setty J V, Singh S, Subba Reddy V V. Comparison of the effect of topical fluorides on the commercially available conventional glass ionomers, resin modified glass ionomers and polyacid modified composite resins- An in vitro study. J Indian Soc Pedo Prev Dent2003;21:55-69

28. Dunkin RT, Chambers DW. Gingival response to class $\mathrm{V}$ composite resin restorations. J Am Dent Assoc 1983; 106:482-4.

29. Yip HK, To WM, Smales RJ: Effects of artificial saliva and APF gel on the surface roughness of newer glass ionomer cements. Oper Dent 2004;29:661-8.

30. Akselsen JP, Afseth J, Rolla G: In vitro damage to glass ionomer cements by fluoride ions. Caries Res 1987;21:188.

31. Crisp S, Lewis BG, Wilson AD: Characterization of glass ionomer cements. A study of erosion and water absorption in both neutral and acidic media. J Dent 1980;8:68-74.
32. Matsuys S, Matsuya Y, Yamaamoto Y, Yamane M: Erosion process of glass ionomer cement in organic acids. Dent Mater 1984;3:210-9.

33. EI-Badrawy WAG, McComb D, Wood RE. Effect of home-use fluoride gels on glass ionomer and composite restorations. Dent Mater 1993;9:63-7.

34. Topaloglu-Ak A, Cogulu D, Kocatas Ersin N, Sen $\mathrm{BH}$. Microhardness and surface roughness of glass ionomer cements after APF and $\mathrm{TiF}_{4}$ applications. J Clin Pediatr Dent 2012;37:45-52.

35. García-Godoy F, García-Godoy A, García-Godoy F. Effect of APF Minute-Foam on the surface roughness, hardness, and micromorphology of high-viscosity glass ionomers. J Dent Child 2003;70:19-23.

36. Diaz-Arnold AM, Wistrom DW, Swift EJ Jr: Topical fluorides and glass ionomer micro hardness. Am J Dent 1995:8:134-6.

37. Al Zraikat H, Palamara JE, Messer HH, Burrow MF and Reynolds EC. The incorporation of casein phosphopeptide-amorphous calcium phosphate into a glass ionomer cement. Dent Mater 2011;27:235-43.

38. Zalizniak I, Palamara JE, Wong RH, Cochrane NJ, Burrow MF and Reynolds EC. Ion release and physical properties of CPP-ACP modified GIC in acid solutions. J Dent 2013;41:449-54.

39. Lucas ME, Arita $K$ and Nishino M. Toughness, bonding and fluoride-release properties of hydroxyapatite-added glass ionomer cement. Biomaterials 2003;24:3787-94.

40. Moshaverinia A, Ansari S, Moshaverinia M, Roohpour N,Darr JA and Rehman I. Effects of incorporation of hydroxyapatiteand fluoroapatite nanobioceramics into conventional glass ionomer cements (GIC). Acta Biomater 2008;4:432-40.

\section{Yazışma Adresi:}

Selçuk Savaş

İzmir Kâtip Çelebi Üniversitesi

Diş Hekimliği Fakültesi Pedodonti AD

Aydınlık Evler Mahallesi, Cemil Meriç Cad, 6780 Sokak. No:48, 35640-Çiğli / İZMİR

Tel: +90 (232) 3254040

Fax: +90 (232) 3252535

E-mail: selcuksavas1983@hotmail.com 